\title{
A THEORY OF THE WORST FORMS OF CHILD LABOUR
}

\author{
Sylvain E. Dessy Stéphane Pallage *
}

December 2003

\begin{abstract}
Although intuitive and morally compelling, a ban on the worst forms of child labour in poor countries is unlikely to be welfare improving. We show that harmful forms of child labour have an economic role: by maintaining wages for child labour high enough, they allow human capital accumulation in poor countries. Unless appropriate mechanisms are designed to mitigate the decline in child labour wages caused by reduced employment options for children, a ban on harmful forms of child labour will likely prove undesirable. We perform our analysis within a simple model of parental investment in children's education.
\end{abstract}

Key words: Child labour, human capital, learning-by-doing, welfare, development JEL classification: 100, J20, O01

${ }^{*}$ Dessy: Department of Economics and CIRPEE, Université Laval, Sainte-Foy, QC, G1K 7P4, Canada. 418-656-2131 (ext.6672), sdes@ecn.ulaval.ca. Pallage: Department of Economics and CIRPEE, Université du Québec à Montréal, C.P. 8888 Succursale Centre-Ville, Montreal, QC, H3C 3P8, Canada. 514-987-3000 (ext.8370). Fax: 514-987-8494, pallage.stephane@uqam.ca. This paper was circulated previously under the title 'Why Banning the Worst Forms of Child Labour Would Hurt Poor Countries.' We thank the Editor, Gerard van den Berg and two anonymous referees for very insightful comments. The paper also benefited from comments by Kaushik Basu, Patrick Francois, Garance Genicot, Clément Lemelin, Dilip Mookherjee, Michel Robe and participants to the 2001 NEUDC Conference at Boston University. Financial support from the Social Sciences and Humanities Research Council of Canada is gratefully acknowledged. 
Child labour is as old as mankind. In the second half of the 20th century, an international consensus developed on the elimination of the practice based upon the desire to protect children and favour their mental and cognitive development. Echoing this consensus, in 1973, the International Labour Organisation (ILO) designed a convention establishing at fifteen years the minimum age for admission to employment (Convention C138). ${ }^{1}$

In fact, policy was preceding research by many years. Recently, however, economic researchers, both theoretically ${ }^{2}$ and empirically, ${ }^{3}$ have gained significant ground on the understanding of the causes of child labour. There is now a widespread agreement that poverty is a major determinant of child labour. Moreover, all forms of child labour are no longer seen as bad for children. Some help build "character" by teaching punctuality, discipline and rigour which are socially valuable qualities (Ray, 2000) - newspaper delivery, baby-sitting and farm work, for instance. Some others may even provide valuable learning-by-doing (Boyden, Ling, \& Myers, 1998; Beegle, Dehejia, \& Gatti, 2003). This set of facts has led to the admission that child labour should be tolerated in poor countries, at least in its non-hazardous forms.

In current policy discussions of child labour, the emphasis has now shifted towards the worst forms of child labour - those that expose children to physical and psychological stress, like drug-trafficking, deep-sea fishing, prostitution and pornographic activities. In 1999, a new ILO convention is designed to ban those forms of child labour only (Convention C182).

Policy is yet again ahead of research. In fact, the important question of why the worst forms of child labour exist is still unanswered. Rogers \& Swinnerton (2002) is the only other paper to our knowledge trying to address this issue. Rogers \& Swinnerton (2002) emphasise the case where parents have incomplete information on the type of work (hazardous or non-hazardous) in which their child is involved. Based upon this premise, they argue that banning the worst forms of child labour can improve efficiency by acting as an information-elicitation mechanism. In following this approach, they implicitly assume that only ignorance or deception can explain why altruistic parents consent to harmful child labour. We wish to make the point that even, absent ignorance or deception, there is a general equilibrium-based argument for parents to choose the worst forms

\footnotetext{
${ }^{1}$ Convention $\mathrm{C} 138$, although ratified by most poor countries, has failed to eliminate child labour. In many African countries, the proportion of children involved in labour activities still ranges from 20 to $30 \%$, depending on the age-bracket considered (ILO, 1996). In Latin America and the Caribbean, approximately 10\% of children ages 10-14 are reported to participate in the labour market in 1995, 13\% in Asia.

${ }^{2}$ See, e.g., Basu \& Van (1998), Ranjan (1999, 2001), Basu (1999, 2000), Baland \& Robinson (2000), Dessy (2000), Dessy \& Pallage (2001), López-Calva (2002).

${ }^{3}$ See, e.g., Grootaert \& Kanbur (1995), Canagarajah \& Coulombe (1997), Grootaert (1998), Moe (1998), Anker (2000), Cigno \& Rosati (2000, 2002), Edmonds (2003, 2004).
} 
of child labour. This argument, we believe, can change the way policy makers approach the elimination of these forms of child labour. In the present paper, we argue that altruistic parents may in fact voluntarily choose the worst forms of child labour, such as prostitution and deep-sea fishing over other non-harmful jobs for their children. The reasons are simple, they are poor and these activities pay well, much better than farm work and other forms of child labour (see, e.g., Rialp, 1993). We build a model in which such wage premium for the worst forms of child labour arises in equilibrium.

As in Baland \& Robinson (2000), we analyse the interaction between child labour and human capital accumulation. In Baland \& Robinson (2000), those two activities are substitutes: the more child labour children perform, the lower their human capital, hence earning potential, as adults. The authors try to rationalise the emergence of child labour in spite of its inefficiency. We offer a counter-argument to this point. If schooling entails a cost - fees, books, tutoring, etc - and markets are incomplete, then child labour and schooling may in fact be complements. We find such complementarity in equilibrium for poor countries.

Arguably, that there be voluntary consent and a wage premium might not be sufficient reasons to reject bans on the worst forms of child labour. In particular, if there are positive spillovers from human capital accumulation, bans on the harmful forms of child labour, by forcing children into less harmful forms, might help achieve higher average human capital and possibly higher welfare. Although by all means intuitive, this is in fact far from straightforward. As we argue in this paper, the existence of the worst forms of child labour has an economic role. It helps maintain the wage for the better forms sufficiently high so as to allow child labourers to work less and spend more time at school.

We develop a simple theory of the worst forms of child labour based upon three essential premises. First, the model environment features household poverty, which puts pressure on children to help their family make ends meet. Second, parents are altruistic toward their children and make decisions on their behalf. Child labour, if it takes place, is a well-informed choice of parents. Third, the worst forms of child labour compromise the human capital prospects of children involved, for example, by reducing their learning ability in school, or by causing their endowment of human capital to depreciate. In such an environment, the worst forms of child labour would not emerge in equilibrium unless they are better remunerated than the "good" forms.

That there ought to be wage compensation, albeit not necessarily perfect, for the worst forms of child labour, is consistent with empirical evidence. According to Rialp (1993), girls ages 14-16 become involved in prostitution in the Philippines largely because prostitution is well paid, with a 
median income of around US $\$ 53$ per week. On a yearly basis, this represents about three times the per capita gross domestic product of the Philippines in 1993 (World Bank, 1998). Boys, who turn to deep-sea fishing, are also attracted by the higher wage. Mullings (1999) documents that one sexual encounter with a young prostitute in Jamaica is priced between 40 and 150 times the hourly wage in a blue-collar manufacturing job. Further evidence can be found in Mayorga \& Velásquez (1999), for Colombia, and in Solé (1993), for teenage male prostitutes in Paris. Earnings premia over other forms of work are also important determinant in the choice of young adolescents to enter the crime business (Freeman, 1996; Grogger, 1998).

\section{Choice or Victimisation?}

Critics of our theory might point at victimisation as the reason why, in developing countries, many girls are found in brothels, escort agencies, or pornographic industries, while many boys are involved in military activities, drug-trafficking, underground mining, and deep-sea fishing. Clearly, the occurrence of slavery and bonded child labour is an important problem (Botte \& Mari, 1993). Bondage and enslavement, however, are criminal activities and are punishable by law in virtually all countries. Legislating on them with another convention might therefore be redundant. ${ }^{4}$

Notwithstanding the above, we wish to make the point that mental, emotional and physical stress, or high assault rates and other poor working conditions are not by themselves sufficient to establish that the worst forms of child labour reflect victimisation, rather than choice - at least on the part of the parents.

A large body of empirical evidence supports our assumption. In a study conducted for the World Bank in Panama, Benin and Cameroon, Narayan (2000) reveals evidence of the moral pain parents face from being driven by poverty to make employment choices, such as prostitution and drug-dealing, that expose their offspring to emotional and physical stress.

In a separate ILO-sponsored investigation on the causes of children's participation in hazardous work in the Philippines, Rialp (1993) reports that in many instances, parents encouraged their children to become involved in prostitution or deep-sea fishing. But in spite of the harsh conditions, children believed that this type of work helped them contribute to family income, and even finance their education. Choice is also central in the description of the juvenile sex sector in the Caribbean (Mullings, 1999; Kempadoo, 1999).

If the supply for the worst forms of child labour is a result of a poverty-constrained choice, then ILO convention C182 may be counter-productive in that it may exacerbate the very poverty that induces altruistic parents to allow their children's participation in this type of work.

\footnotetext{
${ }^{4}$ Moreover, in the case of child bondage, Narayan (2000) and Genicot (2001) show that it can have a voluntary component.
} 


\section{Modelling the Worst Forms of Child Labour}

We consider a two-period economy populated by a continuum of homogeneous parents of total mass normalised to one. Each parent has one period left to live, is endowed with a level of human capital, $h$, and bears one child at the beginning of the period. Henceforth, all secondperiod variables are superscripted with a prime $\left({ }^{\prime}\right)$.

Parents are altruistic towards their offspring, and are lifetime-utility-maximisers, with cardinal utility function over household consumption $(c)$ and child's income when adult $\left(I^{\prime}\right)$. The utility function is given by:

$$
U\left(c, I^{\prime}\right)=\ln c+\beta \ln I^{\prime} \quad 0<\beta<1 .
$$

where $\beta$ is the intergenerational time-discounting factor measuring the degree of parental altruism.

A typical child in this environment is endowed with one unit of time and $h_{0}$ units of human capital. The child's time endowment can be allocated to two possible occupations: schooling or child labour. The latter provides the child with a labour income which he totally contributes to the household. An important feature of this environment is that child labour can occur under two forms. One is a "good" form in the sense that will be made clear below, while the other is harmful to the child either psychologically or physically, or both, and is referred to as the "worst form" of child labour. Another important feature of this environment is that all decisions on child's time use are made by his altruistic parent.

\section{Production}

The unique consumption good can be produced using either child labour, or human capital exclusively. In each period, firms using human capital produce according to a constant-returnsto-scale technology described by:

$$
Y=D H, \quad D>0
$$

where $H$ denotes efficiency units of labour, and $D$ is a scale factor measuring the level of technology used. Following Galor \& Moav (2000), we assume that the rate of technological progress between the first and second periods, $g=\left(D^{\prime}-D\right) / D$, is a function of the second period level of per capita human capital $\bar{h}^{\prime}$ :

$$
g=\psi\left(\bar{h}^{\prime}\right)
$$

where $\psi$ is strictly increasing and strictly concave. The technology described by (2) - (3) exhibits an externality à la Lucas (1988) in the sense that total factor productivity increases with per 
capita human capital. Profit-maximisation by perfectly competitive firms in the human capital intensive sector implies that, in each period, workers are paid the value of their marginal product $D$, which we normalise to 1 : $w=D=1$, in the first period, while in the second,

$$
w^{\prime}=1+\psi\left(\bar{h}^{\prime}\right) \text {. }
$$

For convenience, we assume that the delivery of human capital to firms is restricted to adults. ${ }^{5}$ As a result, children workers cannot take employment in the human capital intensive sector. Firms using child labour have access to two different types of technologies: one is non-harmful to children (type $A$ technology), and the other is harmful (type $B$ technology). If $z$ denotes the type of industry $\left(A\right.$ or $B$ ), output in the child labour intensive sector can be described by: ${ }^{6}$

$$
Y_{z}=\Omega_{z} L_{z}^{\gamma}, \quad 0<\gamma<1, \quad \Omega_{z}>0, \quad z=A, B
$$

$L_{z}$ measures efficiency units of child labour in industry $z$. Resource constraints imply that:

$$
L_{z} \leq n_{z} l_{z}
$$

where $l_{z}$ represents the fraction of time a child spends working and $n_{z}$ denotes the total number of children supplying labour in industry $z$. Profit maximisation by perfectly competitive firms in industry $z$ implies that children in this environment are always paid the value of their marginal product:

$$
\omega_{z}=\gamma \Omega_{z} L_{z}^{\gamma-1}, \quad z=A, B
$$

Were technologies such as (5) to be banned altogether, child labour would no longer be essential for production, as production would then be carried out solely by the human capital intensive sector. However, as long as such technologies exist, their operation will continue to be intensive in child labour. ${ }^{7}$

\section{Human Capital Accumulation Technology}

We now relate the harmful effects of child labour to the child's school performance, via the human capital accumulation process. The motivation for this approach is based on documented evidence ${ }^{8}$

\footnotetext{
${ }^{5}$ This is consistent with the fact that children cannot own a business or drive a lorry.

${ }^{6}$ The assumption of diminishing returns to labour described in (5) does not necessarily imply diminishing returns to scale. In fact the term $\Omega_{z}$ can be defined as $\bar{\Omega}_{z} X^{1-\gamma}$, with $X$ denoting land, a public good as in Galor \& Moav (2000) to abstract from issues of land ownership.

${ }^{7}$ This is not to say that firm owners are evildoers. In fact, higher costs of operating in the formal sector, due, for example, to widespread corruption or excessive regulatory burden, can create en environment favourable to the adoption of such technologies, which make the country's weak institutions equally blameworthy (Dessy \& Pallage, 2003).

${ }^{8}$ See, for example, Anker (2000).
} 
that (i) most children combine work with schooling, and (ii) some but not all forms of child labour are harmful to children in the sense that they interfere with school performance due, for example, to work-related high stress levels, or other health hazards. Therefore we make the following modelling assumptions. First, as is standard in the literature on child labour, work and schooling are the only competing claims on child's time (Glomm, 1997; Baland \& Robinson, 2000). Second, we assume that the production process of the industry in which a child is employed affects his initial endowment of human capital, $h_{0}$, either positively (industry $A$ ) or negatively (industry $B$ ). The positive effect associated with industry $A$ reflects the fact that some forms of child labour may lead to learning-by-doing (Boyden et al., 1998). In contrast, the negative effects on the child's human capital endowment associated with industry $B$ reflects the empirical evidence that some forms of child labour, "either by their nature or the circumstances in which they are carried out, are likely to harm the health, safety or morals of children" (ILO, 1999). Included in this category are child prostitution, pornographic activities and drug-trafficking, which expose children to physical or psychological abuses, and thus can affect their cognitive and social development.

In our model, we therefore assume that a child who works a fraction $l_{z}$ of his time in industry $z$ will augment his endowment of human capital by $\delta_{z} l_{z} h_{0}$. The resulting human capital level will be further augmented by $\phi_{z} e_{z}$ units acquired through formal schooling, where $e_{z}$ denotes the fraction of child's time allocated to schooling with $l_{z}+e_{z}=1$, and $\phi_{z}>0$ is an efficiency parameter measuring the productivity of schooling as a human capital accumulation mechanism. The total level of human capital accumulated by a child working in either industry is thus given by:

$$
h_{z}^{\prime}= \begin{cases}\phi_{z} e_{z}+\left[1+\delta_{z}\left(1-e_{z}\right)\right] h_{0} & \text { if } e_{z}<1 \\ \phi+h_{0} & \text { if } e_{z}=1\end{cases}
$$

This human capital accumulation technology implies that a child receiving full-scholarisation (i.e., $\left.e_{z}=1\right)$, has a level of human capital $\phi+h_{0}$. The following assumption formalises the sense in which work in industry $B$ is harmful to the child:

Assumption 1. (i) $\delta_{A}>0$ and $\delta_{B}<0$; (ii) $\phi \geq \phi_{A}>\phi_{B}>0$.

Part (i) of assumption 1 states that child labour generates positive learning-by-doing effects when it is carried out in industry $A$ (the "good" industry); but it generates "negative" learning-bydoing effects when it is carried out in industry $B$ (the "bad" industry). The term $\delta_{A}\left(1-e_{A}\right) h_{0}$ (respectively, $\left.\delta_{B}\left(1-e_{B}\right) h_{0}\right)$ can therefore be interpreted as human capital gained (respectively, lost) through a child's participation in industry $A$ (respectively, $B$ ). Part (ii) of assumption 1 , 
states that, ceteris paribus, a child who works in the "good" industry is more productive in school than one who works in the "bad" industry.

To illustrate the harmful effects of type $B$ child labour, note that if a parent chooses $e_{B}=0$, then his child's human capital level will be $h_{B}^{\prime}=\left(1+\delta_{B}\right) h_{0}<h_{0}$, by assumption 1 , a loss from the child's endowment. Therefore, for a child laborer in industry $B$ to accumulate human capital, or even maintain his initial endowment, his parent must sufficiently invest in education; i.e., he must warrant his child a level of education, $e_{B}$, such that $\phi_{B} e_{B}+\left[1+\delta_{B}\left(1-e_{B}\right)\right] h_{0} \geq h_{0}$. In contrast, a child who works full time in industry $A$ will achieve human capital $h_{A}^{\prime}=\left(1+\delta_{A}\right) h_{0}>$ $h_{0}$. Since, in general, formal education is perceived as the most effective mechanism for human capital accumulation, we make the following assumption:

Assumption 2. For all $\delta_{A} \in(0,1), \phi_{A}-\delta_{A} h_{0}>0$.

Assumption 2 states that schooling is more productive than learning-by-doing as a human capital accumulation mechanism.

\section{Parental Decision Problem}

Unlike in Rogers \& Swinnerton (2002), in our model, all parents, when making their decisions on child's time allocation and on which industry $z$ to enlist their children, know the pros and cons of each option. The budget constraint faced by a parent whose child works in industry $z$ is given by:

$$
c_{z}+\rho e_{z} \leq I+\left(1-e_{z}\right) \omega_{z}
$$

where $I=w h$ denotes adult labour income, $\rho$ is a positive factor that converts one unit of the unique consumption good into units of education, and $\omega_{z}$ denotes the market wage for type $z$ child labour $(z=A, B)$. Each parent has two essential decisions to make. He must decide on his child's time allocation between work and school; then, conditional on choosing child labour, he must select the industry to which his child is to supply labour. Given our normalising $w$ to 1 , the parent's problem is:

$$
\begin{aligned}
& \max _{\langle z\rangle}\left\{\max _{\left\langle e_{z}\right\rangle}\left\{\ln \left[h+\omega_{z}-\left(\omega_{z}+\rho\right) e_{z}\right]+\beta \ln \left(w^{\prime} h_{z}^{\prime}\right)\right\}\right\} \\
& \text { subject to (8) and } e_{z} \in[0,1]
\end{aligned}
$$

The first order condition for an interior solution to the inner problem is given by:

$$
e_{z}: \quad \frac{\omega_{z}+\rho}{h+\omega_{z}-\left(\omega_{z}+\rho\right) e_{z}}=\beta \frac{\phi_{z}-\delta_{z} h_{0}}{\left(\phi_{z}-\delta_{z} h_{0}\right) e_{z}+\left(1+\delta_{z}\right) h_{0}}, \quad z=A, B .
$$


The left-hand-side of (11) denotes the marginal cost of reducing current period consumption in order to increase child's time allocated to schooling by an additional unit; the right-hand-side represents the marginal benefit of the additional schooling through the increase in the child's human capital.

Note that since schooling and labour are the only competing claims on child's time, a child who spends $e_{z}$ units of time in school, will spend the remaining $1-e_{z}$ units working in industry $z$. Therefore, for the analysis to be carried out in this paper, it is important to understand, from the view-point of a poor household, how changes in the child labour wage affect parental allocation of child's time between these two competing claims. By poor household, we mean one for which the parent's labour income satisfies:

$$
I=h<\rho
$$

A poor parent, according to this definition, is one who cannot afford full scholarisation for his child, i.e. cannot afford $e_{z}=1$ because his labour income does not cover the cost of full-scholarisation. Such parent is driven to the use of child labour by poverty. Our definition of poverty is consistent with existing empirical evidence from poor countries, that the poor are not only those that do not work, but more often those whose labour income is too low (Narayan, 2000).

Proposition 1 Let assumptions 1-2 and condition (12) hold simultaneously. If, in addition, parents are not too poor in the sense that

$$
h \geq \theta_{A} \beta^{-1} \rho \text { with } \theta_{z}=\frac{\left(1+\delta_{z}\right) h_{0}}{\left(\phi_{z}-\delta_{z} h_{0}\right)}, z=A, B
$$

then all children in this environment will combine work and schooling as their childhood activities.

Proof. Note that the parameters $\delta_{z}, \phi_{z}$, and $h_{0}$ can always be chosen such that $\theta_{A} \beta^{-1}<1$. To prove the proposition, it suffices to show that $e_{z}$ is indeed an interior solution to (11) when all the above conditions hold simultaneously. To prove this result, we first solve the above first order condition for an interior solution. We find:

$$
e_{z}=\eta\left[\frac{h+\omega_{z}}{\rho+\omega_{z}}-\theta_{z} \beta^{-1}\right], \quad \quad \text { all } z
$$

where, $\eta=\beta /(1+\beta)<1$. Now, by condition (12), the first term inside the bracket is less than unity, while the second is positive by assumptions 1 and 2 . Hence $e_{z}<1$. Furthermore, by condition (13), it follows that:

$$
\frac{h+\omega_{z}}{\rho+\omega_{z}}-\theta_{z} \beta^{-1}>0,
$$


implying that $e_{z}>0$. Hence the result.

Proposition 1 is consistent with empirical evidence that in many environments children combine schooling and work (Ravallion \& Wodon, 2000; Coulombe, 2001). Condition (13) simply states that parents in this environment are not too poor in the sense that, even in the absence of an economic value for child's time, they can afford some schooling for their child. However, for these parents, full-scholarisation is a luxury good, as formally established in the following proposition and its corollary. ${ }^{9}$

Proposition 2 (Complementarity) Under assumptions 1 - 2 and conditions (12) and (13), child's time allocated to schooling is an increasing function of the child labour wage, irrespective of the industry in which the child works.

Proof. The result simply follows from differentiating (14) with respect to $\omega_{z}$, and applying condition (12).

Proposition 2 implies that allocating a larger proportion of child's time to schooling is a "luxury" - as this term is use in Basu \& Van (1998) - that a poor parent can afford only when the child earns a high enough wage to contribute to the cost of education. A higher child labour wage, by allowing the child to earn more while working fewer hours, may allow him to attend school more often: child labour and schooling are in effect complementary. This result corroborates reports by Boyden et al. (1998) that in many instances, working helps children pay for their school. Our analysis suggests, in accordance with much empirical evidence, that parental poverty is the reason why many children must combine work with schooling.

Corollary 1 Irrespective of the industry in which they are employed, children in this environment have higher human capital prospects the higher the child labour wage.

Proof. We have to show that for all $z=A, B, \partial h_{z}^{\prime} / \partial \omega_{z}>0$ is always true. Using the human capital accumulation technology specified in (8) and re-arranging terms, we find:

$$
h_{z}^{\prime}=\left(\phi_{z}-\delta_{z} h_{0}\right) e_{z}+\left(1+\delta_{z}\right) h_{0}
$$

Clearly, $\partial h_{z}^{\prime} / \partial \omega_{z}>0 \forall z$ if Proposition 2 holds.

\footnotetext{
${ }^{9}$ Since $I_{z}^{\prime}=w^{\prime} h_{z}^{\prime}$, our choice of logarithmic utility (1) is necessary to obtain the independence of child's time allocation policy from $w^{\prime}$, the future wage rate for human capital. While this independence is purely a technicality, departing from it would make the analysis more complex, without adding any significant qualitative insight: indeed, if there is dependence on $w^{\prime}$, its effect on child's time allocation policy is the same regardless of the industry in which the child is employed.
} 
Combining (14) and (15), we obtain the optimal human capital accumulation rule:

$$
h_{z}^{\prime}=\eta\left(\frac{\phi_{z}-\delta_{z} h_{0}}{\rho+\omega_{z}}\right)\left[h+\omega_{z}+\left(\rho+\omega_{z}\right) \theta_{z}\right] .
$$

Likewise, combining the budget constraint with (14) yields a household's optimal consumption:

$$
c_{z}=\frac{1}{1+\beta}\left[h+\omega_{z}+\left(\rho+\omega_{z}\right) \theta_{z}\right] .
$$

Let $V\left(h, z, \omega_{z}, w^{\prime}\right)$ be the value accruing to a parent who sends his child to work in industry $z$ :

$$
V\left(h, z, \omega_{z}, w^{\prime}\right)=(1+\beta) \ln \left[h+\omega_{z}+\left(\rho+\omega_{z}\right) \theta_{z}\right]-\beta \ln \left(\rho+\omega_{z}\right)+\beta \ln w^{\prime}+R_{z},
$$

where $R_{z}=\beta \ln \left[\left(\phi_{z}-\delta_{z} h_{0}\right) \eta\right]-\ln (1+\beta)$.

The future labour wage, $w^{\prime}$, has a positive effect on the parent's value. In equilibrium, this positive effect will prove determinant in analysing the welfare implications of a ban on child labour in industry $B$.

We now characterise each altruistic parent's decision on the industry $(A$ or $B)$ in which his child should work. The parent makes such decision by comparing the total values generated by both options. A parent will find it optimal to choose industry $A$ over industry $B$ if $V\left(h, A, \omega_{A}, w^{\prime}\right)>$ $V\left(h, B, \omega_{B}, w^{\prime}\right)$.

Let $\vartheta\left(h, \omega_{A}, \omega_{B}, w^{\prime}\right)$ denote the net value gain from choosing industry $A: \vartheta\left(h, \omega_{A}, \omega_{B}, w^{\prime}\right)=$ $V\left(h, A, \omega_{A}, w^{\prime}\right)-V\left(h, B, \omega_{B}, w^{\prime}\right)$. We have:

$$
\vartheta\left(h, \omega_{A}, \omega_{B}, w^{\prime}\right)=(1+\beta) \ln \left[\frac{h+\omega_{A}+\left(\rho+\omega_{A}\right) \theta_{A}}{h+\omega_{B}+\left(\rho+\omega_{B}\right) \theta_{B}}\right]-\beta \ln \left[\frac{\rho+\omega_{A}}{\rho+\omega_{B}}\right]+\Delta,
$$

where: $\Delta=\beta \ln \left[\frac{\phi_{A}-\delta_{A} h_{0}}{\phi_{B}-\delta_{B} h_{0}}\right]$.

To further simplify the analysis, we normalise $\phi_{z}$ and $\delta_{z}$ such that $\Delta=0$. This is done through the following assumption:

Assumption 3. $\phi_{A}-\phi_{B}=\left(\delta_{A}-\delta_{B}\right) h_{0}$.

Since $\left(\delta_{A}-\delta_{B}\right) h_{0}>0$, assumption 3 states that the difference in learning ability between a child working in type $A$ environment and one working in type $B$ is high enough. As a result, $\Delta=0$ and the net value gain from choosing industry $A$ becomes:

$$
\vartheta\left(h, \omega_{A}, \omega_{B}, w^{\prime}\right)=(1+\beta) \ln \left[\frac{h+\omega_{A}+\left(\rho+\omega_{A}\right) \theta_{A}}{h+\omega_{B}+\left(\rho+\omega_{B}\right) \theta_{B}}\right]-\beta \ln \left[\frac{\rho+\omega_{A}}{\rho+\omega_{B}}\right]
$$

Proposition 3 Under assumptions 1-3 and condition (12), the net value from choosing industry $A$ increases (decreases) with an increase in industry $A$ 's (industry $B$ 's) child labour wage. 
Proof. The proof follows from the differentiation of (19) with respect to $\omega_{A}$ and $\omega_{B}$ respectively, and the use of (12).

Now, suppose that $\vartheta\left(h, \omega_{A}, \omega_{B}, w^{\prime}\right)>0$, then all parents will want to choose industry $A$ over industry $B$. As a result, the supply of child labour in industry $A$ will rise. Consequently, this industry's child labour wage, $\omega_{A}$, will decline, while that of industry $B$ will rise. By Proposition 3 , the net value from choosing industry $A$ will decline. This process will go on until, in equilibrium, parents are indifferent between industries: $\vartheta\left(h, \omega_{A}, \omega_{B}, w^{\prime}\right)=0$.

\section{Equilibrium Child Labour Profile}

In this section, we characterise a competitive equilibrium for this two-period economy, keeping track of the distribution of children workers across industries. In particular, we formalise the coexistence between non-harmful and harmful forms of child labour. We do so in the context of a poor country, one in which parents have incomes that satisfy conditions (12) and (13).

A competitive equilibrium for this two-period economy is a collection of endogenous variables $\left[\left(e_{z}, h_{z}^{\prime}, L_{z}, n_{z}, \omega_{z}\right)_{z=A, B} ; H^{\prime}, w^{\prime}\right]$ such that:

(i) given $\left(h, \omega_{A}, \omega_{B}, w^{\prime}\right)$,

$$
\vartheta\left(h, \omega_{A}, \omega_{B}, w^{\prime}\right)=0 ;
$$

(ii) the demand for child labour in industry $z$ is profit maximising:

$$
L_{z}=\left(\frac{\gamma \Omega_{z}}{\omega_{z}}\right)^{\zeta}, \forall z, \text { where } \zeta=\frac{1}{1-\gamma}>0
$$

(iii) $w^{\prime}$ satisfies (4), i.e. $w^{\prime}=1+\psi\left(\bar{h}^{\prime}\right)$, where

$$
\bar{h}^{\prime}=n_{A} h_{A}^{\prime}+n_{B} h_{B}^{\prime},
$$

and $n_{z}$ denotes the total number of children working in industry $z$;

(iv) $n_{A}+n_{B}=1$;

(v) all markets clear, i.e., $H^{\prime}=\bar{h}^{\prime}$ and

$$
L_{z}=\left(1-e_{z}\right) n_{z}, \quad \forall z .
$$

Since in equilibrium parents are indifferent between industries, the relation between the wage rate in the "good" and in the "bad" industries is implicitly given by condition (20).

Proposition 4 Under assumptions 1 - 2 and conditions (12) and (13), in equilibrium, the two forms of child labour do not coexist unless $\omega_{B}>\omega_{A}$. 
Proof. To prove this proposition, suppose we have $\omega_{A}>\omega_{B}$. Consider two allocations of consumption, work and schooling times, $\hat{x}_{A}$ and $\hat{x}_{B}$, solving the problem of parents in work environments $A$ and $B$ respectively given the wages $\omega_{A}$ and $\omega_{B}$, and leaving the parents indifferent. Consider next an alternative allocation $\tilde{x}$ in which children work and attend school for the same number of hours as in $\hat{x}_{B}$, but instead of working in environment $B$, they work in environment $A$. This allocation is feasible and yields a higher consumption level together with a higher future human capital for children. It must be that $\tilde{x}$ is strictly preferred to $\hat{x}_{B}$ by parents in type $B$ environment. Since, in equilibrium, they are indifferent between $\hat{x}_{A}$ and $\hat{x}_{B}$, by transitivity of preferences, it must also be that $\tilde{x}$ is strictly preferred to $\hat{x}_{A}$, which means that parents in type $A$ environment were not optimising when choosing $\hat{x}_{A}$, which contradicts our premise. The same reasoning applies to the case where $\omega_{A}=\omega_{B}$. Hence it must be that $\omega_{B}>\omega_{A}$.

Proposition 4 implies that when parents are altruistic towards their offspring and are aware of the harmful effects of child labour in industry $B$, this industry must pay a higher wage than industry $A$ to attract child labourers. In other words, in spite of poverty, altruistic parents would not send their children to work in the "bad" industry, unless there is compensation. As a matter of fact, it is the need to alleviate poverty, combined with the liquidity constraint in financing education that make such monetary compensation acceptable to altruistic parents. How high the wage in industry $B$ needs to be in order for parents to be indifferent between industries is an important question, to which we turn now. Denote by $\mu\left(\omega_{A}, \omega_{B}\right)=\omega_{B}-\omega_{A}$ the required wage compensation. The following corollary to proposition 4 characterises this wage compensation.

Corollary 2 Under assumptions 1-3 and conditions (12) and (13), the wage compensation necessary to make parents indifferent between industries $A$ and $B$ is such that:

$$
\mu\left(\omega_{A}, \omega_{B}\right)>\left(\rho+\omega_{A}\right)\left[\frac{\theta_{A}-\theta_{B}}{1+\theta_{B}}\right] .
$$

Proof. Given assumptions 1-3, the term $\left(\theta_{A}-\theta_{B}\right) /\left(1+\theta_{B}\right)$ is strictly positive. Furthermore, that parents are indifferent between industries implies:

$$
\frac{h+\omega_{A}+\left(\rho+\omega_{A}\right) \theta_{A}}{h+\omega_{B}+\left(\rho+\omega_{B}\right) \theta_{B}}=\left[\frac{\rho+\omega_{A}}{\rho+\omega_{B}}\right]^{\eta} .
$$

Since by proposition $4, \omega_{B}>\omega_{A}$, we have $\left[\frac{\rho+\omega_{A}}{\rho+\omega_{B}}\right]^{\eta}<1$ implying that:

$$
\frac{h+\omega_{A}+\left(\rho+\omega_{A}\right) \theta_{A}}{h+\omega_{B}+\left(\rho+\omega_{B}\right) \theta_{B}}<1 .
$$

The result then simply follows from appropriately re-arranging terms.

The next proposition further characterises the equilibrium time allocation and its impact on the accumulation of human capital. 
Proposition 5 Under assumptions 1-3 and conditions (12), in equilibrium, children working in industry $B$ receive more schooling than those in industry $A$, but accumulate less human capital.

Proof. To prove the first claim, it suffices to show that $e_{B}>e_{A}$, whenever the above conditions hold. Suppose not, i.e., $e_{B} \leq e_{A}$. Using the definition of $\theta_{z}$ and (14), this weak inequality can be re-written as:

$$
\frac{(\rho-h)\left(\omega_{B}-\omega_{A}\right)}{\left(\rho+\omega_{B}\right)\left(\rho+\omega_{A}\right)} \leq \frac{\theta_{B}-\theta_{A}}{\beta},
$$

The right-hand side of (26) is strictly negative by assumptions $1-2$. This leads to a contradiction, since $(\rho-h)\left(\omega_{B}-\omega_{A}\right)>0$, in equilibrium. To prove the second claim, we have to show that $h_{A}^{\prime}>h_{B}^{\prime}$. Suppose not, i.e., $h_{A}^{\prime} \leq h_{B}^{\prime}$. Using (15) and re-arranging terms yields:

$$
\frac{h+\omega_{A}+\left(\rho+\omega_{A}\right) \theta_{A}}{h+\omega_{B}+\left(\rho+\omega_{B}\right) \theta_{B}} \leq \frac{\rho+\omega_{A}}{\rho+\omega_{B}} \frac{\phi_{B}-\delta_{B} h_{0}}{\phi_{A}-\delta_{A} h_{0}}=\frac{\rho+\omega_{A}}{\rho+\omega_{B}}
$$

by assumption 3. It follows from (25) that:

$$
\left[\frac{\rho+\omega_{A}}{\rho+\omega_{B}}\right]^{\eta} \leq \frac{\rho+\omega_{A}}{\rho+\omega_{B}} .
$$

Since $\eta<1$ by definition, this contradicts the fact that $\omega_{B}>\omega_{A}$ in equilibrium.

Taken literally, proposition 5 might lead to the conclusion that a ban on type $B$ child labour, in the spirit of ILO Convention C182, would be human capital enhancing in poor countries and likely welfare improving. The point we wish to make, however, is that such a conclusion should not be validated irrespective of the labour market consequences of reduced employment options for children. One should keep in mind that, in a poor economy, children have higher human capital prospects, the higher the child labour wage (corollary 1 ). This is mainly due to the fact that the higher the wage, the fewer the number of hours a child needs to work in order to help support the household. To the extent that both types of child labour would have coexisted absent the ratification of ILO Convention C182, a ban on type $B$ child labour, and the sudden influx of child labourers it will generate in type $A$ market, will likely drive down the wage in this market. How this decline in child labour wage will affect welfare needs to be carefully assessed. In Section 4 , we provide a thorough welfare analysis. Since much of the wage drop depends on the number of children working in both industries, however, we first characterise the equilibrium allocation of child labourers.

\subsection{Equilibrium Allocation of Children Workers}

Combining equilibrium conditions (21) and (23) yields the number of children in industry $z$ :

$$
n_{z}=\left(\frac{\gamma \Omega_{z}}{\omega_{z}}\right)^{\zeta}\left(1-e_{z}\right)^{-1} \text {. }
$$


Obviously, how many children are active in either industry depends upon the equilibrium child labour wage profile, a characterisation of which is therefore key to our understanding of the distribution of child labourers. Equilibrium conditions (i), (ii), (iv) and (v) imply that the equilibrium child labour wage profile $\left(\omega_{A}, \omega_{B}\right)$ solves the following system of two equations and two unknowns:

$$
\left\{\begin{array}{l}
\Gamma\left(\omega_{A}, \omega_{B}\right)=0 \\
\Upsilon\left(\omega_{A}, \omega_{B}\right)=\lambda
\end{array}\right.
$$

where:

- $\Gamma\left(\omega_{A}, \omega_{B}\right) \equiv \frac{h+\omega_{A}+\left(\rho+\omega_{A}\right) \theta_{A}}{h+\omega_{B}+\left(\rho+\omega_{B}\right) \theta_{B}}-\left[\frac{\rho+\omega_{A}}{\rho+\omega_{B}}\right]^{\eta}$

- $\Upsilon\left(\omega_{A}, \omega_{B}\right) \equiv\left(\frac{1}{\omega_{A}}\right)^{\zeta} \frac{(1+\beta)\left(\rho+\omega_{A}\right)}{\beta(\rho-h)+\left(\rho+\omega_{A}\right)\left(1+\theta_{A}\right)}+\left(\frac{\alpha}{\omega_{B}}\right)^{\zeta} \frac{(1+\beta)\left(\rho+\omega_{B}\right)}{\beta(\rho-h)+\left(\rho+\omega_{B}\right)\left(1+\theta_{B}\right)}$,

- $\alpha=\Omega_{B} / \Omega_{A}$ and $\lambda=\left(\gamma \Omega_{A}\right)^{-\zeta}$.

The parameter $\alpha$ is a measure of the relative productivity of type $B$ child labour: $\alpha>1$ means that, ceteris paribus, child labour is relatively more productive in type $B$ market. As one can expect, the value of $\alpha$ will be important in the wage differential between both types of child labour. It will therefore be a key parameter in the welfare analysis of the ban. System (28) is clearly non-linear, and there is no hope of obtaining an explicit analytical characterisation of the equilibrium wage profile. However, since both equations comprising the system are linearly independent, a solution, hence an equilibrium, always exists.

Using equation (27), the equilibrium number of children employed in each industry is given by:

$$
\left\{\begin{array}{l}
n_{B}=\lambda^{-1}\left(\frac{\alpha}{\omega_{B}}\right)^{\zeta} \frac{(1+\beta)\left(\rho+\omega_{B}\right)}{\beta(\rho-h)+\left(\rho+\omega_{B}\right)\left(1+\theta_{B}\right)} \\
n_{A}=1-n_{B}
\end{array}\right.
$$

\section{Welfare Effects of a Ban}

In this section, we turn to the welfare effects of banning the worst forms of child labour in the context in which the coexistence of both types of child labour is driven by poverty. In our model, this amounts to banning industry $B$, thus leaving industry $A$ as the sole source of employment for children. The welfare evaluation, which we want to report here highlights the following findings. Much of whether the ban on the worst forms of child labour is welfare improving depends on the extent of the economy-wide human capital externality. In the extreme scenario, in which there is no such externality, we show that the ban on type $B$ child labour is always welfare reducing. 
The ban implies a reduction of child labour wage on the remaining market and imposes a new constraint on parental choices. In the opposite scenario, in which there exist human capital spillovers, one would expect the conclusion to be less strong. Since the externality introduces non-linearities in our model, we revert to numerical examples to show that, for otherwise very reasonable parameter choices, it takes implausibly strong externality effects for our conclusion to be reversed. We now derive these results step by step. After some preliminary discussions, we focus on both scenarios described above.

To analyse the welfare effects of the ban on type $B$ child labour, we compare the parental values obtained respectively in absence of the ban and when the ban is enforced. It is important to note that absent the ban, parents achieve the same level of welfare irrespective of the industry in which their child is employed. Indeed, in equilibrium, parents are indifferent as to which form of child labour their child should supply. Therefore, in absence of legislative intervention, we can measure this welfare level by the value accruing to a parent who chooses industry $A$. Using (4) and (18), this value can be written as:

$$
\begin{aligned}
\bar{V}\left(h, A, \omega_{A}, \bar{h}^{\prime}\right) & =(1+\beta) \ln \left[h+\omega_{A}+\left(\rho+\omega_{A}\right) \theta_{A}\right]-\beta \ln \left(\rho+\omega_{A}\right) \\
& +\beta \ln \left[1+\psi\left(\bar{h}^{\prime}\right)\right]+R_{A},
\end{aligned}
$$

where $\bar{V}\left(h, A, \omega_{A}, \bar{h}^{\prime}\right)=V\left(h, A, \omega_{A}, 1+\psi\left(\bar{h}^{\prime}\right)\right)$, and $\bar{h}^{\prime}=n_{A} h_{A}^{\prime}+n_{B} h_{B}^{\prime}$.

When the ban is enforced, industry $A$ becomes the only employment option for children. Henceforth, variables with an asterisk $(*)$ denote equilibrium variables after the selective ban is imposed on industry $B ; \omega_{A}^{*}$ is thus the child labour wage resulting from this institutional change and $\bar{h}^{\prime *}=h_{A}^{\prime *}$, the resulting economy-wide average human capital.

Let $V^{*}\left(h, \omega_{A}^{*}\right)$ be the value accruing to the representative parent when restricted to industry $A$ :

$$
\begin{aligned}
V^{*}\left(h, \omega_{A}^{*}\right)= & (1+\beta) \ln \left[h+\omega_{A}^{*}+\left(\rho+\omega_{A}^{*}\right) \theta_{A}\right] \\
& -\beta \ln \left(\rho+\omega_{A}^{*}\right)+\beta \ln \left[1+\psi\left(h_{A}^{\prime *}\right)\right]+R_{A} .
\end{aligned}
$$

Therefore, the net value accruing to a parent from supporting the ban on industry $B, \vartheta^{*}\left(h, \omega_{A}^{*}, \omega_{A}, \omega_{B}\right)=$ $V^{*}\left(h, \omega_{A}^{*}\right)-\bar{V}\left(h, A, \omega_{A}, \omega_{B}\right)$, is given by:

$$
\begin{aligned}
\vartheta^{*}\left(h, \omega_{A}^{*}, \omega_{A}, \omega_{B}\right)= & (1+\beta) \ln \left[\frac{h+\omega_{A}^{*}+\left(\rho+\omega_{A}^{*}\right) \theta_{A}}{h+\omega_{A}+\left(\rho+\omega_{A}\right) \theta_{A}}\right]-\beta \ln \left(\frac{\rho+\omega_{A}^{*}}{\rho+\omega_{A}}\right) \\
& +\beta \ln \left[\frac{1+\psi\left(h_{A}^{\prime *}\right)}{1+\psi\left(\bar{h}^{\prime}\right)}\right] .
\end{aligned}
$$


For parents to benefit from the ban, it must be that the above expression is positive. Due to diminishing returns to labour in industry $A$, it is clear that $\omega_{A}^{*}<\omega_{A}$. We are now equipped to tackle the welfare analysis. We review successively two scenarios, one in which there is no externality associated with human capital accumulation, one in which there is. ${ }^{10}$

\subsection{No Externality}

A world without human capital spillovers, in our model, is one in which per capita human capital has no effect on the rate of technical progress. More formally, this implies that for all $h, \psi(h)=\sigma$, where $\sigma \geq 0$. Consequently, the ratio $\left[1+\psi\left(h_{A}^{\prime *}\right)\right] /\left[1+\psi\left(\bar{h}^{\prime}\right)\right]$ equals 1 , so that the net value from supporting a ban on industry $B$ reduces to:

$$
\vartheta^{*}\left(h, \omega_{A}^{*}, \omega_{A}, \omega_{B}\right)=(1+\beta) \ln \left[\frac{h+\omega_{A}^{*}+\left(\rho+\omega_{A}^{*}\right) \theta_{A}}{h+\omega_{A}+\left(\rho+\omega_{A}\right) \theta_{A}}\right]-\beta \ln \left(\frac{\rho+\omega_{A}^{*}}{\rho+\omega_{A}}\right) .
$$

We can state and prove our last analytical result.

Proposition 6 Under condition (12), in absence of externality, banning the worst forms of child labour is welfare reducing.

Proof. We want to show that $\vartheta^{*}\left(h, \omega_{A}^{*}, \omega_{A}, \omega_{B}\right)<0$, whenever $\psi(h)=\sigma$ for all $h$. This amounts to showing that:

$$
\frac{h+\omega_{A}^{*}+\left(\rho+\omega_{A}^{*}\right) \theta_{A}}{h+\omega_{A}+\left(\rho+\omega_{A}\right) \theta_{A}}<\left(\frac{\rho+\omega_{A}^{*}}{\rho+\omega_{A}}\right)^{\beta /(1+\beta)}
$$

Now since $\omega_{A}^{*}<\omega_{A}$, due to diminishing returns to child labour in industry $A$, we have:

$$
\left(\frac{\rho+\omega_{A}^{*}}{\rho+\omega_{A}}\right)^{\beta /(1+\beta)}>\frac{\rho+\omega_{A}^{*}}{\rho+\omega_{A}}
$$

using the fact that $\beta \in(0,1)$. Thus, to show that condition (34) is true, it suffices to show that the following inequality holds:

$$
\frac{h+\omega_{A}^{*}+\left(\rho+\omega_{A}^{*}\right) \theta_{A}}{h+\omega_{A}+\left(\rho+\omega_{A}\right) \theta_{A}}<\frac{\rho+\omega_{A}^{*}}{\rho+\omega_{A}}
$$

It can be established that the latter condition reduces to:

$$
-\left(\omega_{A}-\omega_{A}^{*}\right)(\rho-h)<0
$$

which is true since $\omega_{A}^{*}<\omega_{A}$ and condition (12) is satisfied.

\footnotetext{
${ }^{10}$ Which scenario is more plausible is an empirical matter.
} 
Note that condition $\psi(h)=\sigma, \forall h$, means that the rate of technical progress is exogenous and independent of per capita human capital. In such an environment, banning the worst forms of child labour is counter-productive. In an environment in which the rate of technical progress does

depend upon the level of per capita human capital, however, the ratio $\left[1+\psi\left(h_{A}^{\prime *}\right)\right] /\left[1+\psi\left(\bar{h}^{\prime}\right)\right]$ is different from 1: if it is bigger than 1, the welfare effects of banning the worst forms of child labour are ambiguous. The level of this ratio is a matter of empirical investigation, as well as whether there is an economy-wide human capital externality. The following section solves numerical examples to illustrate the welfare consequences of the ban under this scenario.

\subsection{The Externality Scenario: A Numerical Analysis}

In an environment with human capital externality, the net gain from supporting the ban on industry $B$ has the more general form given in (32). If the term $\beta \ln \left[\left(1+\psi\left(h_{A}^{\prime *}\right)\right) /\left(1+\psi\left(\bar{h}^{\prime}\right)\right)\right]$ is non-positive, the results of subsection 4.1 hold and the conclusion is immediate. The sign of that term, however, is not straightforward. Numerical examples are needed to assess the welfare effects of the ban in this case. For our numerical analysis, we select parameter values in such a way that assumptions $1-3$ hold, in addition to all the conditions underlying our propositions and corollaries: $\rho=40 ; h=0.5 \rho ; h_{0}=1 ; \delta_{A}=-\delta_{B}=10 ; \phi_{A}=150 ;$ and $\Omega_{A}=10$. We choose $\beta=0.5$ in accordance with estimates from the empirical literature on the intergenerational discount rate. In addition, we set $\gamma=0.6$, implying that the elasticity of production to a change in the demand for child labour in industry $z$ is $60 \%$, which is quite realistic for most labour-intensive technologies. Finally, in line with Galor \& Moav (2000), we choose the following functional form for the rate of technological progress:

$$
\psi\left(\bar{h}^{\prime}\right)=\tau{\overline{h^{\prime}}}^{\varphi}
$$

with $\varphi=0.9$, and $\tau \in\{0.01,0.05,0.1\}$. This choice of parameters, purposely, gives a lot of weight to the externality. The rate of technological progress implied by our parametrisation is in the neighbourhood of $20 \%$ when $\tau=0.01,100 \%$ when $\tau=0.05$ and $200 \%$ when $\tau=0.1$. We show that even for these highly implausible figures, there is little chance of finding the ban on the worst forms of child labour to be Pareto improving.

Based upon these values, we solve system (28) to obtain the equilibrium wage profile $\left(\omega_{A}, \omega_{B}\right)$. We next compute the level of human capital accumulated by a child employed in either industry using equation (16). The distribution of children across industries is then obtained from (29), while the average future human capital level in the economy follows from (22). 
For values of $\alpha$ between 0.5 and 1.6, the first six columns of Table 1 characterise conditions on the child labour market prior to the ban. Note that for $\alpha<1$ labour productivity is higher, ceteris paribus, in industry $A$ than in industry $B$. The reverse is true for $\alpha>1$. The difference between columns 3 and 2 in Table 1 is the wage premium for the worst forms of child labour. The interested reader can verify that this premium satisfies condition (24). Columns 4 and 5 give the distribution of children across industries. Column 6 reports the average human capital in the economy absent the ban.

The next task is to compute the net parental value, $\vartheta^{*}\left(h, \omega_{A}^{*}, \omega_{A}, \omega_{B}\right)$, from supporting the ban on industry $B$, using (32). Assuming enforcement of the ban, all child labourers now work in industry $A$, therefore $n_{A}=1$. The new equilibrium wage is then given by $\omega_{A}^{*}=\gamma \Omega_{A}\left(1-e_{A}^{*}\right)^{\gamma-1}$. Using the above specified parameter values, this new equilibrium wage level is $\omega_{A}^{*}=6.36$ corresponding to a level of per capita human capital $h_{A}^{* *}=\bar{h}^{\prime *}=30.203$. Columns 7-9 of Table 1 report the net welfare gain from banning the worst forms of child labour, for values of the externality parameter $\tau$ equal to $0.01,0.1$ and 0.5 respectively.

Following our computations above, it appears clearly from Table 1 (6th column) that the ban on the worst forms of child labour is human capital-enhancing. This might be one of the reasons why such a ban appears intuitively compelling. The last two columns of Table 1 , however, draw a completely different picture. For the ban to be welfare improving, it takes values of externality parameter $\tau$ implausibly high. For any value of $\tau$ such that the implied rate of technological progress is less than $100 \%$, the ban is welfare reducing. ${ }^{11}$

This numerical exercise shows that the welfare consequences of banning the worst forms of child labour are non-trivial. In particular, if a reasonable number of children are involved in the activities to be banned, the drop in child labour wages might lead to a worsening of the condition of poor families and a reduction in the number of hours children spend at school. Admittedly, the average human capital in the economy might end up greater, but the process towards this result might turn out to be socially very painful. ${ }^{12}$

\footnotetext{
${ }^{11}$ This conclusion is very robust to parameter changes.

${ }^{12}$ In the analysis above, we only consider interior solutions to the parents' problem. The only cases in which parents in our model would go to the corner solution (with no schooling), are cases of extreme poverty where survival is at stake. In fact, our result gets even stronger at the corner because poverty is then so stark that any device that raises household income (e.g., the worst forms of child labour) is highly desirable. Rather than focusing on an extreme case, we show that even for countries that are not in such a state of despair, banning the worst forms of child labour would not necessarily be a Pareto improvement.
} 


\section{Discussion and Conclusion}

When a ban is used as the sole instrument to eradicate the worst forms of child labour, policy makers run the risk of mixing child labour resulting from a choice and child labour resulting from enslavement or deception. Choice by children or altruistic parents would disappear if economic conditions were better. Poverty alleviation techniques would eliminate that segment of the worst forms of child labour. Neglecting better focused policies would amount to punishing those whose misery is so stark that horrible forms of child labour become the best option. For child labour resulting from abuse - e.g., deceived parents or abducted children - enforcement of bans, existing or other, could be the appropriate complement. We want to argue, however, that poverty alleviation measures will also reduce the incidence of such crimes. Poverty makes abduction and deception easier. Abducted children are oftentimes so because they are left roaming in the streets. Deception is facilitated if parents are naive, uneducated and driven by poverty to consider offers by perfect strangers to look after their child.

Clearly, an international consensus on the elimination of the worst forms of child labour is easy to reach - it is morally compelling. Our point is that using legislation such as ILO Convention C182 for this purpose, however, may do more harm than good. By curing the symptoms, one may fail to address the causes of harmful forms of child labour, of which poverty is a nonnegligeable component. Poverty alleviation measures are thus a much better suited and more natural mechanism. In fact, blindly banning harmful forms of child labour would be ignoring that such activities have an economic role, that of keeping the wage for other forms of child labour sufficiently high to help poor families finance their children's education.

A food-for-education program, however, might help boost support for a ban on harmful forms of child labour. Because it relaxes the liquidity constraint of the poor, this food-for-education program may induce more time spent at school, which may be sufficient to offset the negative effects of the sudden increase in the supply of child labourers on type $A$ job market, following the ban. The present model, however, is not equipped to take into account the adverse effects foodfor-education programs may have on fertility decisions, for instance, or the stigma that may be attached to them, often leading parents to disregard the option to subscribe to them. Moreover, food-for-education programs cannot be evaluated in a partial equilibrium setting. The question of their financing needs to be addressed, which may temper our conclusion. One can argue that such programs should be financed by international aid. Pallage \& Zimmermann (2003) have studied the possibility to use international transfers to buy out child labour. They quantify the Pareto optimal transfers and show that the elimination of child labour, though possible, is not 
a short term objective. The transfers needed to immediately eradicate child labour significantly exceed the willingness to pay of rich countries.

We worked throughout with the assumption of identical parents. One might argue that this lack of heterogeneity in the distribution of human capital across parents weighs heavily on our results. Such is not the case, however. If our results indicate a welfare reducing ban, and the country satisfies a condition resembling Condition (12), it implies that more than half its population would suffer from the ban on the worst forms of child labour. The ban, in such country, would therefore never be part of a voting equilibrium.

Our results should not be interpreted as suggesting that child prostitution or dangerous work are good and should be encouraged. They suggest that these activities have an economic role in poor countries which cannot be ignored. Banning them without taking appropriate steps may have adverse effects on the well-being of families. 


\section{References}

Anker, R. (2000). Conceptual and research frameworks for the economics of child labor and its elimination. ILO/IPEC Working Paper: International Labour Organization.

Baland, J.-M. \& Robinson, J. A. (2000). Is child labor inefficient?. Journal of Political Economy, 108(4), 663-679.

Basu, K. (1999). Child labor: cause, consequence, and cure, with remarks on international labor standards. Journal of Economic Literature, 37(3), 1083-1119.

Basu, K. (2000). The intriguing relation between adult minimum wage and child labour. The Economic Journal, 110 (March), C50-C61.

Basu, K. \& Van, P. H. (1998). The economics of child labor. American Economic Review, 88(3), 412-427.

Beegle, K., Dehejia, R., \& Gatti, R. (2003). Why should we care about child labour?. Manuscript, World Bank.

Botte, M.-F. \& Mari, J.-P. (1993). Le prix d'un enfant: 4 ans dans l'enfer de la prostitution enfantine à Bangkok. Éditions Robert Laffont, Paris.

Boyden, J., Ling, B., \& Myers, W. (1998). What Works for Working Children. UNICEF, Italy and Rada Barnen, Sweden.

Canagarajah, S. \& Coulombe, H. (1997). Child labor and schooling in Ghana. The World Bank, Working Paper 1844.

Cigno, A. \& Rosati, F. C. (2000). Why do Indian children work, and is it bad for them?. IZA Discussion Paper No. 115: Bonn.

Cigno, A. \& Rosati, F. C. (2002). Child labour, education, and nutrition in rural India. World Development, 7(1), 65-83.

Coulombe, H. (2001). Child labor and schooling in West Africa: a three-country study. Doctoral Thesis: University of Warwick.

Dessy, S. E. (2000). A defense of compulsory measures against child labor. Journal of Development Economics, 62(1), 261-275.

Dessy, S. E. \& Pallage, S. (2001). Child labor and coordination failures. Journal of Development Economics, 65(2), 469-476.

Dessy, S. E. \& Pallage, S. (2003). Taxes, inequality and the size of the informal sector. Journal of Development Economics, 70(1), 225-233.

Edmonds, E. V. (2003). The response of child labor supply to anticipated income. Manuscript, Dartmouth College.

Edmonds, E. V. (2004). Does child labor decline with improving economic status?. Journal of Human Resources. forthcoming.

Freeman, R. B. (1996). Why do so many young American men commit crimes and what might we do about it?. Journal of Economic Perspectives, 10(1), 25-42.

Galor, O. \& Moav, O. (2000). Ability-biased technological transition, wage inequality, and economic growth. Quarterly Journal of Economics, 115(2), 469-497.

Genicot, G. (2001). Bonded labor and serfdom: a paradox of voluntary choice. Journal of Development Economics, 67, 101-127.

Glomm, G. (1997). Parental choice of human capital investment. Journal of Development Economics, 53(1), 99-114.

Grogger, J. (1998). Market wages and youth crime. Journal of Labor Economics, 16(4), 756-791. 
Grootaert, C. (1998). Child labor in Côte d'Ivoire: incidence and determinants. The World Bank, Working Paper 1905.

Grootaert, C. \& Kanbur, R. (1995). Child labour: an economic perspective. International Labour Review, 134(2), 187-203.

ILO (1996). Economically Active Populations: Estimates and Projections, 1950-2010. International Labor Organization: Geneva.

ILO (1999). C182 Worst Forms of Child Labour Convention. International Labor Organization: Geneva.

Kempadoo, K. (1999). Continuities and change: five centuries of prostitution in the Caribbean. In Sun, Sex, and Gold: Tourism and Sex Work in the Caribbean, pp. 3-36. Kamala Kempadoo (Ed.), Rowman and Littlefield Publishers, Lanham, Maryland and Oxford, England.

López-Calva, L. F. (2002). A social stigma model of child labor. Estudios Economicos, 17(2), 193-217.

Lucas, R. E. J. (1988). On the mechanics of economic development. Journal of Monetary Economics, 22, 3-32.

Mayorga, L. \& Velásquez, P. (1999). Bleak pasts, bleak futures: life paths of thirteen young prostitutes in Cartagena, Colombia. In Sun, Sex, and Gold: Tourism and Sex Work in the Caribbean, pp. 3-36. Kamala Kempadoo (Ed.), Rowman and Littlefield Publishers, Lanham, Maryland and Oxford, England.

Moe, K. S. (1998). Fertility, time use, and economic development. Review of Economic Dynamics, 1(3), 699-718.

Mullings, B. (1999). Globalization, tourism and the international sex trade. In Sun, Sex, and Gold: Tourism and Sex Work in the Caribbean, pp. 55-80. Kamala Kempadoo (Ed.), Rowman and Littlefield Publishers, Lanham, Maryland and Oxford, England.

Narayan, D. (2000). Voices of the Poor: Can Anyone Hear Us? Oxford University Press for The World Bank: Oxford.

Pallage, S. \& Zimmermann, C. (2003). Buying out child labor. Manuscript, Université du Québec à Montréal and University of Connecticut.

Ranjan, P. (1999). An economic analysis of child labor. Economics Letters, 64(1), 99-105.

Ranjan, P. (2001). Credit constraints and the phenomenon of child labor. Journal of Development Economics, 64(1), 81-102.

Ravallion, M. \& Wodon, Q. (2000). Does child labour displace schooling? Evidence on behavioural responses to an enrollment subsidy. The Economic Journal, 110, C158-C175.

Ray, R. (2000). Child labor, child schooling, and their interaction with adult labor: empirical evidence from Peru and Pakistan. World Bank Economic Review, 14(2), 347-367.

Rialp, V. (1993). Children and Hazardous Work in the Philippines. International Labour Office: Geneva.

Rogers, C. A. \& Swinnerton, K. A. (2002). A theory of exploitative child labor. Manuscript, U.S. Department of Labor.

Solé, J. (1993). L'âge d'or de la prostitution: de 1870 à nos jours. Librairie Plon: Paris.

World Bank (1998). World Development Indicators (CD-ROM). Washington: World Bank. 
Table 1: Results from the numerical analysis

\begin{tabular}{ccccccccc}
\hline$\alpha$ & $\omega_{A}$ & $\omega_{B}$ & $n_{A}$ & $n_{B}$ & $h^{\prime}$ & $\vartheta^{*}(\tau=.01)$ & $\vartheta^{*}(\tau=.05)$ & $\vartheta^{*}(\tau=.1)$ \\
\hline & & & & & & & & \\
0.5 & 6.49 & 11.48 & 0.95 & 0.05 & 30.038 & $-1.08 \times 10^{-3}$ & $-2.42 \times 10^{-4}$ & $1.64 \times 10^{-4}$ \\
0.6 & 6.56 & 11.56 & 0.93 & 0.07 & 29.948 & $-1.72 \times 10^{-3}$ & $-4.23 \times 10^{-4}$ & $2.047 \times 10^{-4}$ \\
0.7 & 6.65 & 11.66 & 0.90 & 0.10 & 29.839 & $-2.57 \times 10^{-3}$ & $-7.10 \times 10^{-4}$ & $1.88 \times 10^{-4}$ \\
0.8 & 6.77 & 11.79 & 0.86 & 0.14 & 29.711 & $-3.64 \times 10^{-3}$ & $-1.12 \times 10^{-3}$ & $0.97 \times 10^{-4}$ \\
0.9 & 6.90 & 11.95 & 0.82 & 0.18 & 29.571 & $-4.96 \times 10^{-3}$ & $-1.73 \times 10^{-3}$ & $-1.60 \times 10^{-4}$ \\
1 & 7.07 & 12.14 & 0.77 & 0.23 & 29.420 & $-6.57 \times 10^{-3}$ & $-2.56 \times 10^{-3}$ & $-6.08 \times 10^{-4}$ \\
1.1 & 7.26 & 12.35 & 0.72 & 0.28 & 29.265 & $-8.49 \times 10^{-3}$ & $-3.67 \times 10^{-3}$ & $-1.33 \times 10^{-3}$ \\
1.2 & 7.48 & 12.60 & 0.67 & 0.33 & 29.112 & $-1.08 \times 10^{-2}$ & $-5.14 \times 10^{-3}$ & $-2.40 \times 10^{-3}$ \\
1.3 & 7.72 & 12.88 & 0.62 & 0.38 & 28.965 & $-1.34 \times 10^{-2}$ & $-6.98 \times 10^{-3}$ & $-3.87 \times 10^{-3}$ \\
1.4 & 8.00 & 13.19 & 0.57 & 0.43 & 28.828 & $-1.63 \times 10^{-2}$ & $-9.24 \times 10^{-3}$ & $-5.77 \times 10^{-3}$ \\
1.5 & 8.30 & 13.53 & 0.52 & 0.48 & 28.708 & $-1.97 \times 10^{-2}$ & $-1.20 \times 10^{-2}$ & $-8.18 \times 10^{-3}$ \\
1.6 & 8.63 & 13.91 & 0.47 & 0.53 & 28.605 & $-2.34 \times 10^{-2}$ & $-1.59 \times 10^{-2}$ & $-1.11 \times 10^{-2}$ \\
\hline
\end{tabular}

